\title{
A nova psiquiatria transcultural $e$ a reformulação na relação entre as palavras e as coisas
}
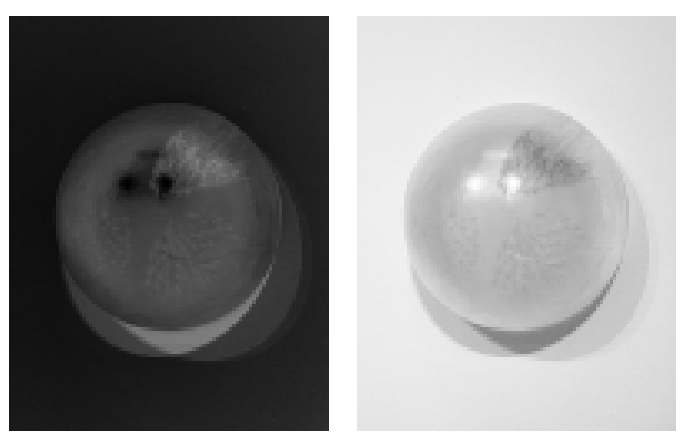

\author{
Maria Fernanda Tourinho Peres ${ }^{1}$ \\ Naomar Monteiro de Almeida Filho ${ }^{2}$
}

PERES, M. F. T.; ALMEIDA-FILHO, N. The new transcultural psychiatry and the reformulation of the relationship between words and things. Interface - Comunic., Saúde, Educ., v.9, n.17, p.275-85, mar/ago 2005.

The so called "new transcultural psychiatry" proposes a reformulation of the relationship between words and things in the field of medicine. This reformulation consists of a polissemic reading of the illness experience. In this article our aim is to question this proposal and point out its limits, through a foucaultian perspective, Considering the importance of discursivity in the theoretical work of the author, it is possible to radicalize the reformulation of the relationship between words and things; between discourse and its meaning and between speech and the speaking subject. Through the notion of discursive practice, discursivity gains materiality and produces forms of subjectivity. It is in the discursive order that the illness experience is initiated and that the illness subject is constructed; that illness emerges as an event and makes itself present as "disgovernance".

KEY WORDS: new transcultural psychiatry; illness experience; disgovernance; mental health; medical anthropology.

A chamada "nova psiquiatria cultural" propõe uma reformulação na relação entre as palavras e as coisas no campo médico. Esta reformulação consiste em uma leitura polissêmica da experiência de adoecimento. Neste artigo nosso objetivo é, a partir de uma leitura foucaultiana, problematizar esta proposta $e$ apontar seus limites. Considerando o enfoque dado à discursividade no trabalho teórico de Foucault, torna-se possível uma radicalização na reformulação entre palavras e coisas; entre discurso e sentido; entre fala e sujeito falante. Pela noção de prática discursiva, o discurso ganha materialidade e produz formas de subjetividades. É na ordem discursiva que se instaura a experiência de adoecimento e que é instituído o sujeito adoecido; que a doença surge como acontecimento e se faz presente como "desgoverno".

PALAVRAS-CHAVE: nova psiquiatria transcultural; experiência de adoecimento; desgoverno; saúde mental; antropologia médica.

* Elaborado a partir de Peres (2001), tese de doutorado defendida no Programa de Pós-Graduação do Instituto de Saúde Coletiva, Universidade Federal da Bahia, com bolsa do CNPq.

\footnotetext{
${ }^{1}$ Pesquisadora, Núcleo de Estudos da Violência, Universidade de São Paulo, São Paulo, SP. <mftperes@usp.br>

${ }^{2}$ Reitor, Universidade Federal da Bahia; Professor titular, Instituto de Saúde Coletiva, Universidade Federal da Bahia, Salvador, Ba. <naomar@ufba.br>
}

${ }^{1}$ Núcleo de Estudos da Violência - USP

Av. Prof. Lúcio Martins Rodrigues, travessa 4, Bloco 2

Cidade Universitária, São Paulo - SP

05508-900 
PERES, M. F. T.; ALMEIDA-FILHO, N.

\section{Introdução}

Encontramos na antropologia médica uma linha de estudos que se diz crítica das abordagens tradicionais sobre a relação entre doença mental $e$ cultura. Essa linha de estudos, que se autodenomina "nova psiquiatria transcultural" tem como eixo comum a preocupação com a contextualização das categorias diagnósticas e a compreensão da experiência de adoecimento enquanto experiência singular-individual fortemente enraizada nos valores culturais, sistemas simbólicos e na organização sócio-política (Bibeau E Corin, 1994; Good, 1994; Littlewood, 1990; Fabrega, 1989; Young, 1982; Good \& Good, 1982, 1980; Kleinman, 1977). Ou seja, pretende, em uma abordagem crítica do modelo biomédico ocidental, compreender a experiência de adoecimento como ponto de articulação entre indivíduo $e$ coletividade. Desta forma, busca romper com o "etnocentrismo" das velhas abordagens, afirmando-se como sensível às diferentes realidades nas quais se desenvolvem os fenômenos do adoecer psíquico. O objetivo último desses estudos é tornar a prática médico-psiquiátrica mais eficaz, ao incorporar as concepções populares sobre doença no processo terapêutico.

No entanto, é possível perceber na proposta da "nova psiquiatria transcultural" a perpetuação de certos elementos criticados e questionados no modelo biomédico ou, como dizem Good \& Good (1980), na racionalidade da medicina contemporânea. Neste artigo iremos nos limitar a discutir a "reformulação na relação entre as palavras e as coisas" proposta por Good \& Good (1980, p.171). Para os autores, só é possível uma reformulação na teoria e racionalidade médicas mediante uma reconceitualização fundamental entre a ordem das palavras e a ordem das coisas no campo médico. Esta reformulação consiste em trazer ao modelo biomédico a possibilidade de uma leitura polissêmica do adoecimento, na qual o sintoma (significante) não tenha como referente único a alteração biológica (significado), mas uma rede de significados culturalmente compartilhados. A partir da relação com a rede que compõe a cultura, os indivíduos atribuem sentido aos sintomas e vivem sua doença como uma experiência que se situa no limite entre o singular e o compartilhado, o individual e o coletivo. É esta experiência que constitui objeto de atenção médica, cujo trabalho é, para Good \& Good, essencialmente hermenêutico. Trata-se de buscar, para além dos sintomas manifestos, o sentido que se constrói na articulação da história individual e do contexto sócio-cultural.

Bibeau \& Corin (Bibeau 1993; 1992; 1988; Bibeau \& Corin, 1994; Corin 1993; 1989; Corin et al., 1993; 1990) vão além desta proposta ao tentarem articular nos sistemas de signos, significados e práticas ( $\mathrm{S} / \mathrm{ssp}$ ) três dimensões da realidade: a experiência individual, o universo sóciosimbólico e o desenvolvimento histórico-social. Os autores também privilegiam o sentido em sua proposta, porque este é produzido não apenas em uma relação sincrônica com o contexto sócio-cultural, mas em uma relação diacrônica, considerando o contexto sócio-cultural em sua dimensão histórica. Desta forma, o sintoma ou a doença têm como referente um sentido que é individual e coletivo a um só tempo; sentido mobilizado pelo sujeito adoecido que, no entanto, é dado pela cultura, pela organização social, pelo devir histórico. O sujeito utiliza-se de sentidos e os transforma 
em sua experiência individual. Assim, tanto na concepção de rede semântica (Good \& Good, 1980, 1982), como na teoria dos S/ssp, as narrativas sobre a doença constituem via de acesso aos sentidos que compõem o substrato cultural no qual as histórias individuais se desenvolvem (Corin, 1993).

Ao afirmar que as narrativas individuais funcionam como "via de acesso" a sentidos compartilhados, Corin (1993) parte do pressuposto de que os sentidos são dados culturalmente - portanto, preexistentes aos sujeitos -, sendo a palavra o seu representante na linguagem. É preciso ir além da palavra dita e buscar os múltiplos sentidos que lhe são referentes. Ocorre, desta forma, um movimento interpretativo que parte da palavra (narrativa) para o sentido que ela porta. Cabem, neste momento, alguns questionamentos: o que há de novo nesta proposta? Ao propor uma leitura polissêmica a nova psiquiatria transcultural estabelece, realmente, uma reformulação na relação entre as palavras e as coisas no campo médico?

\section{Michel Foucault $e$ as práticas discursivas}

Segundo Foucault (1981), até finais do século XVI, a semelhança desempenhou um papel construtor no saber da cultura ocidental: era em termos de semelhança que se realizavam as interpretações de textos, aorganização de símbolos, o conhecimento das coisas e a "arte de representá-las". Neste sentido, tomando como base a semelhança, a linguagem operava como repetição. No jogo da semelhança, diz, estabelecese no mundo a ordem do mesmo, ou seja, uma relação de similitude estabelecida entre as coisas da natureza, desde a mais simples à mais complexa. $O$ ponto para nós importante refere-se à relação entre a linguagem $e$ as coisas, ou seja, o mundo pode ser comparado ao homem que fala: as coisas são reconhecidas pelas marcas em sua superfície, marcas deixadas por Deus como sinais que devem ser decifrados pelo homem. Esses sinais são a parte visível da semelhança existente entre as coisas, possibilidade mesma de podermos percebê-las. O mundo nos fala por meio desses signos, os quais significam à medida que se assemelham com o que indicam. As palavras são para as coisas como marcas presentes em sua superfície. Palavras são, assim, coisas a decifrar e devem ser estudadas como coisas da natureza.

Há, no saber do século XVI, um cruzamento entre olhar e linguagem, uma ausência de distinção entre observado e relatado, entre o que se vê e o que se lê. Neste sentido, o saber constitui-se sob a forma do comentário: uma vez que a natureza é um tecido ininterrupto de palavras e marcas, de narrativas e discursos, o saber sobre a natureza é sempre um comentário de um texto primeiro que foi lido e interpretado (Foucault, 1981). Esta relação entre linguagem e coisa modifica-se na idade clássica: a linguagem deixa de ser a escrita material da coisa, passando ao regime dos signos representativos. No funcionamento da representação, a linguagem perde sua solidez de coisa inscrita no mundo. O signo, que era a relação entre palavra e coisa, passa a ter seu valor pela possibilidade de representar. O que mudou na segunda metade do século XVII foi o regime dos signos, ou seja, a relação do signo com seu conteúdo não está mais na ordem da coisa, não é mais um dado a ser decifrado. O signo é constituído apenas por um ato de 
conhecimento, e só então passa a significar. Formado por um ato de conhecimento, o signo é, no classicismo, a união de duas idéias: uma que representa e uma representada.

No século XVIII estabelece-se nova descontinuidade, assinalando o fim da época clássica o que, segundo Foucault (1981), possibilitou o surgimento do Homem. O Homem aparece como medida de todas as coisas, não mais em relação de igualdade com os seres do mundo. Será agora um sujeito entre objetos, e logo sujeito e objeto: o que tenta compreender o mundo sob a forma de trabalho, linguagem e vida, e a si mesmo em sua finitude. A linguagem que o envolve lhe é exterior e com historicidade própria, assim como o trabalho $e$ a vida. A relação da representação consigo mesma $e$ as relações de ordem que ela permite determinar fora de toda medida quantitativa, passam agora por condições exteriores à própria representação, ou seja, a ligação da representação de um sentido à de uma palavra deve ser feita com referência a leis gramaticais de linguagem. A língua representa agora a partir da gramática. O fundamental deste acontecimento, que marca a nova descontinuidade, não se encontra no nível dos objetos visados, analisados $e$ explicados, e nem na maneira de conhecer e racionalizar estes objetos, mas na relação da representação com o que nela é dado. O mundo é subjacente, exterior e mais profundo que a representação. Esta mudança na relação entre palavras e coisas se reflete na prática e no saber médicos: um novo objeto surge, assim como surgem um novo sujeito de conhecimento e uma nova prática.

Em "O Nascimento da Clínica", Foucault (1963) narra o nascimento da medicina moderna a partir de um acontecimento populacional por definição: a epidemia. A epidemia estabelece uma ruptura, marca o surgimento de um novo discurso, de uma nova prática e de um novo objeto no campo da medicina. Diz Foucault: "Novos objetos serão dados ao saber médico na medida em que e ao mesmo tempo que o sujeito de conhecimento se reorganiza, se modifica e se põe a funcionar de uma maneira diferente" (p.89). Há, desta forma, uma reformulação na relação entre as palavras e as coisas, nascendo o que pode ser chamado de "a racionalidade médica contemporânea" com seu "olhar calculador" que vê para além da superfície do corpo e do tempo presente (Foucault,1963). Esta racionalidade médica tem como suporte uma certa teoria da linguagem que vê no sintoma/signo o referente da doença: o sintoma/signo é o significante cujo significado é a doença. Aí reside a transformação discursiva; aí se encontra a nova mirada do médico clínico: o sintoma se torna signo; o sintoma é transformado em elemento significante. Na racionalidade clínica não há mais diferença essencial entre a doença, o sintoma e o signo, uma vez que signo e sintoma são o visível da doença e representam, na sucessão das manifestações patológicas, sua história natural; na racionalidade clínica a doença entra na ordem discursiva ao se dar ao olhar: o visto e o dizível correspondem; o ser da doença, representado nos sintomas, é traduzido para a linguagem descritiva (Foucault, 1963).

O ato descritivo é, de pleno direito, uma tomada do ser e, inversamente, o ser não se dá a ver nas manifestações sintomáticas, portanto essenciais, sem se oferecer ao trabalho de uma linguagem 
que é a palavra mesma das coisas(...) na clínica, ser visto e ser falado comunicam na verdade manifesta da doença de modo que todo o ser está lá. Não há doença para além do visível e, por conseguinte, do enunciável (...) E nesta tomada, se anuncia a ordem dos encadeamentos naturais; a sintaxe da linguagem, longe de perverter as necessidades lógicas do tempo, as restitui na sua articulação originária (...). (Foucault, 1963, p.95)

Temos aqui uma correspondência entre palavras e coisas, entre visível e dito, entre linguagem e mundo: a palavra (signo/sintoma) é a representação verbal da verdade da doença. Mas, de que doença se trata? Trata-se da doença biológica e orgânica, doença que deixa sua marca no corpo e que a anatomia patológica fez surgir e apresentou ao olhar clínico. É isto que Good \& Good (1980) chamam de teoria empiricista da linguagem, teoria que pressupõe uma ligação entre palavras e coisas, entre linguagem $e$ mundo, entre visível e enunciável. A palavra (sintoma/signo) porta um sentido que é a doença. O que a "nova psiquiatria transcultural" propõe é romper com esta relação trazendo para a leitura médica sentidos outros, que vão além da "realidade biológica": sentidos que se formam no ponto de articulação entre o indivíduo e a coletividade; sentidos aos quais o sintoma faz referência; sentidos que o sujeito vivencia e exprime, ao adoecer $e$ ao falar de sua doença.

Desta forma, a leitura polissêmica busca, por meio do sentido, uma verdade por trás das palavras ditas, verdade não enunciada, mas presente, a ser desvelada pelo trabalho interpretativo que vê na cultura a possibilidade mesma desta polissemia: a verdade do sujeito e sua história de vida individual no contexto social e cultural. As palavras ditas sobre a doença $e$ adoecer trazem um sentido que vai além da alteração biológica e biomédica, que se constrói no ponto de articulação indivíduo-contexto e que os sintomas apontam na experiência de adoecimento. Encontramos aí um novo objeto, proposto pela "nova psiquiatria transcultural": a experiência de adoecimento, a enfermidade (illness ${ }^{3}$ ). Os sintomas e seu correlato na linguagem - a narrativa - fazem referência a uma doença que é mais do que

${ }^{3}$ Utilizamos neste artigo a tradução proposta por AlmeidaFilho et al., 1999. alteração biológica, uma enfermidade (illness) como experiência individual $e$ produto cultural. Desta forma, temos uma abertura do sentido no campo médico: a verdade da doença - a ser buscada no trabalho interpretativo que constitui a clínica - é a verdade do corpo doente, do sujeito e sua história, dos códigos culturalmente compartilhados, da organização social e do processo histórico que os engendra.

Com a nova psiquiatria transcultural, ocorre uma complexificação do objeto "doença" como abertura para os múltiplos sentidos que esta experiência porta. Entretanto, a relação entre palavras e coisas não é efetivamente reformulada: apesar da abertura para uma leitura polissêmica, ainda temos uma palavra que carrega um sentido que lhe é preexistente, um sentido dado culturalmente; uma palavra que é representação da verdade da doença. É possível ir além da abertura e pensar a transformação radical desta relação? Será possível pensar em um sentido instituído pela discursividade? Como pensar em um trabalho interpretativo que busca 
PERES, M. F. T.; ALMEIDA-FILHO, N.

analisar não o sentido a que a palavra faz referência, mas o sentido como seu produto? São estas as questões que tentaremos responder, seguindo as "pistas foucaultianas".

\section{O sujeito adoecido produto da discursividade}

Em “A Arqueologia do saber" Foucault (1995a, p.61-2) diz:

(...) as diversas modalidades da enunciação, em lugar de remeterem à síntese ou à função unificante de um sujeito, manifestam sua dispersão (...) renunciaremos a ver no discurso um fenômeno de expressão - a tradução verbal de uma síntese realizada em outro lugar (...) - o discurso não é a manifestação, majestosamente desenvolvida, de um sujeito que pensa, que conhece, que diz (...).

Nesta passagem encontramos algumas pistas importantes para chegarmos à problematização da relação entre palavra e sentido: a) o discurso não é um fenômeno de expressão e não se encontra relacionado à unidade de um sujeito; b) o discurso não é a manifestação de um sujeito que pensa. Temos aqui uma implicação importante daquilo que Foucault chama de formas de subjetivação e a conseqüente leitura da subjetividade humana (Adorno, 2000). Só com esta categoria em mente é possível desvincular o discurso de um sujeito universal, sujeito de razão; só assim é possível pensar neste discurso anônimo (Adorno, 2000). Anônimo, posto que não é produto de um sujeito que pensa e fala, mas, sim, uma materialidade que institui o sujeito.

Foucault afirma em "Le sujet et le pouvoir" (1994a) que a preocupação central de sua obra foi o tema do sujeito. Não do sujeito transcendental, sujeito de razão apriorísticamente dado, mas o sujeito produzido a partir dos jogos de verdade e poder e também das relações consigo mesmo. Há um deslocamento em seu trabalho teórico que descentra a discussão do sujeito para "os diferentes modos de subjetivação do ser humano" ou os "diferentes modos de objetivação que transformam os seres humanos em sujeitos" (Foucault, 1994b, p.223). Há nesta passagem um interessante jogo com as palavras "subjetivação" e "objetivação": o ser humano é transformado em sujeito a partir de sua inscrição em processos objetivantes; trata-se, neste caso, de subjetividades objetivadas por práticas discursivas $e$ não discursivas, pelo engendramento deste ser humano em relações de saber-poder. Segundo Birman (2000, p.81), ao falar em formas de subjetivação Foucault insiste

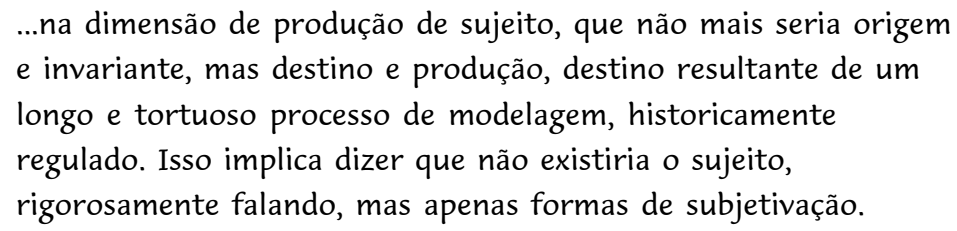

Foucault nos apresenta, então, três modos de subjetivação: as práticas 
divisórias, a classificação científica e as tecnologias de si (Foucault, 1994c; Rabinow, 1999, p.32-5). As práticas divisórias e a classificação científica constituem-se nas relações saber-poder que produzem subjetividades objetivadas, sujeitos que são produzidos a partir do engendramento na rede que se forma entre as formas de saber e as táticas de poder. As tecnologias de si instituem formas de subjetividade a partir da relação que o sujeito estabelece consigo mesmo, a gerência de si. O sujeito é produto da relação entre práticas discursivas e não discursivas, produto, enfim, da relação que estabelece de si para consigo. Aquele sujeito "pura instância fundadora de racionalidade" é olhado criticamente e sua morte é anunciada em "As palavras e as coisas" (Foucault, 1981). Há, em Foucault, uma pulverização do sujeito, uma multiplicidade de sujeitos que são formas de subjetividades.

Temos então um discurso anônimo, discurso que institui formas de subjetividades. Mas não é só. No argumento de Foucault, o discurso também não se constrói a partir de um objeto natural, preexistente à ordem discursiva. Os objetos, assim como os sujeitos, são instituídos pela ordem discursiva, isto é, pelos enunciados que os apresentam. O discurso, nos diz Foucault (1995b, p.48) "(...) não é uma simples superfície de inscrição aonde os objetos se depositam e se superpõem". É isto o que ele nos mostra na "História da Loucura" (1995b): a construção de um objeto - doença mental - e de um sujeito - o doente mental - a partir de um feixe de relações entre enunciados e práticas institucionalizadas. Daí sua noção de práticas discursivas. Tomar o discurso enquanto prática é considerá-lo instância de construção de sujeitos e objetos que são a positividade do discurso e seu produto (Foucault, 1971, p.71-2). São esses sujeitos/objetos que dão a unidade do discurso.

Vejamos então uma primeira conseqüência deste discurso tomado enquanto prática: trata-se de uma "reformulação" na relação entre palavras e coisas, discurso e sentido, fala e sujeito falante. O discurso não é aqui o lugar de representação das coisas e nem via de acesso para o sujeito que fala; o discurso é prática que constrói esse sujeito/objeto no momento mesmo de sua enunciação; sujeito/objeto que dá a unidade do discurso e deve ser buscado em sua materialidade de coisa dita. Diz Foucault (1995c, p.56):

(...) As palavras e as coisas é o título - sério - de um problema; é o título - irônico - do trabalho que lhe modifica a forma, lhe desloca os dados e revela, afinal de contas, uma tarefa inteiramente diferente que consiste em não mais tratar os discursos como conjunto de signos (elementos significantes que remetem a conteúdos ou a representações) mas como práticas que formam sistematicamente os objetos de que falam. Certamente os discursos são feitos de signos; mas o que fazem é mais do que utilizar esses signos para designar coisas (...) é esse mais que é preciso fazer aparecer e é preciso descrever.

E o que é esse "mais" senão a especificidade das práticas discursivas, seus produtos como formas de subjetividade e objetos múltiplos? 
PERES, M. F. T.; ALMEIDA-FILHO, N.

\section{Conclusão: as narrativas populares e o saber das pessoas}

Para concluir, lançamos uma questão: de que forma este discurso que produz formas de subjetividade pode ser trabalhado no sentido de pôr em evidência a "especificidade cultural" de discursos populares sobre o adoecimento mental?

Em "A História da Sexualidade" Foucault demonstra o lugar central ocupado pela medicina na construção da moralidade e no estabelecimento da cultura do cuidado de si. Os modos de relação de si para consigo implicam uma relação de combate, de enfrentamento das paixões visando a liberdade. Ser livre e ter uma conduta ética e moral é ser livre com relação a si mesmo, não se deixar dominar e escravizar pelas paixões, mas sim dominá-las (Foucault, 1994a, p.63). A relação de si para consigo estabelece-se na relação com os outros e com o código moral, explicitamente formulado em doutrinas e saberes institucionalizados, $e$ nas relações habituais dos indivíduos. Em que consiste esse código moral, normativo, senão na cultura? A cultura é, aqui, apresentada sob a forma de práticas morais, jogos de poder e verdade.

O discurso sobre a doença tanto pode ser expresso sob a forma de um saber específico, como sob a forma do que se chama de "conhecimento popular", o saber das pessoas (Foucault, 1999). Em ambos os casos, trata-se de prescrições morais que expressam, a partir de sua negatividade, o correto modo de se relacionar consigo para se conduzir moralmente.

Para Foucault (1999, p.12), o saber das pessoas são os “(..) saberes sujeitados (...) desqualificados como saberes não conceituais, como saberes insuficientemente elaborados (...) abaixo do nível do conhecimento ou da cientificidade requeridos". É o saber daqueles que falam a partir do engendramento nas relações saber-poder, e, neste sentido, nos diz Foucault, “(...) não é um saber comum, um bom senso, mas, ao contrário, um saber particular, um saber local, regional, um saber diferencial, incapaz de unanimidade e que deve sua força apenas à contundência que opõe a todos aqueles que o rodeiam" (Foucault, 1999, p.12); é, neste sentido, um saber de resistência. Ou seja, o saber das pessoas é o saber enunciado pelo sujeitoproduto, pelas formas de subjetividade: sujeito adoecido, sujeito-delinqüente.

A partir desta noção de "saber das pessoas", as narrativas populares podem ser consideradas como parte das artes de governar (Foucault, 1995b). Como? Se consideramos que aqueles que falam sobre a doença do outro fazem-no a partir de sua inserção num feixe de relações que estabelecem consigo, com as coisas e com os outros, fazem-no a partir de sua própria inserção em redes de saber-poder e que, ao falarem do outro, os sujeitos fazem-no a partir desta inscrição no espaço normativo, concluímos que aquele que fala é também um sujeito, no sentido foucaultiano, produto de práticas discursivas e não discursivas e que, ao falar do outro, reproduz estas práticas e institui formas de subjetividade. Ao falar do outro, os sujeitos refletem sobre si, problematizam a própria existência e apresentam, pelo negativo, aquilo que constitui os limites do espaço normativo. Uma vez que falam a partir desta posição de sujeito, é possível compreender a afirmação de Foucault (1999) de que "(...) o saber das pessoas são saberes sem senso comum", ou seja, são saberes produzidos na relação entre práticas discursivas e não discursivas.

Pensamos, como Good \& Good (1980), que é importante uma reformulação na relação entre as palavras e as coisas no campo médico. Foi com isto em 
mente que trouxemos Foucault para o debate. Entretanto, chegamos a um caminho que toma direção inversa: o discurso não representa, mas institui sujeitos e objetos. Se consideramos as narrativas populares, o saber das pessoas, como lugar de inscrição do sujeito adoecido, temos no horizonte uma leitura dessas narrativas que não busca o sentido ao qual ela faz referência nem a verdade do sujeito que fala, mas o sujeito que surge desta enunciação a partir de um acontecimento que instaura uma nova ordem discursiva. $\mathrm{O}$ acontecimento é a crise, ruptura que deixa marcas na vida. Não se trata, contudo, de tomar esta crise como ocasião para reconstruir um passado $e$ buscar suas origens, mas aceitá-la como momento de instauração de algo novo: este sujeito é outro em seu modo de viver desgovernado. A partir desta crise/ ruptura instaura-se a nova ordem discursiva: no discurso sobre o doente e sua doença - saber das pessoas - institui-se um sujeito marcado pelo desgoverno de si, por uma vida alterada na relação que estabelece consigo, com os outros $e$ com as coisas. Assim se constrói uma experiência de adoecimento que é individual e coletiva em sua positividade desgovernada, experiência que se efetiva no momento mesmo de sua enunciação.

Neste sentido, propomos a categoria desgoverno para problematizar o discurso sobre a doença mental. Ser governado é passar a ser sujeito ético e moral e o desgoverno implica negatividade ética, descontrole sobre si, sobre as coisas e sobre os outros. Pensar a doença mental como desgoverno é, assim, tomá-la a partir das relações que o "doente" estabelece consigo, com os outros e com as coisas, relações que se afastam da norma socialmente estabelecida, inseridas na categoria "anormal" pelo saber das pessoas. A categoria desgoverno permite pensar a experiência de adoecimento como uma experiência normativa, posta no espaço que se situa entre o indivíduo e a coletividade. Se continuamos a seguir as "pistas foucaultianas" encontramos mais um elemento para compreender a experiência de adoecimento: a experiência de adoecimento institui, na ordem discursiva, o sujeito adoecido, desgovernado. Temos aqui um sujeito que é produto e não origem. Desta forma, seguir as "pistas foucaultinanas" em uma leitura de discursos populares sobre a doença mental implica repensar a relação entre palavras $e$ coisas, discurso e sentido, fala e sujeito falante.

\section{Referências}

ADORNO, S. Dor e sofrimento, presenças ou ausências na obra de Foucault. In: COLÓQUIO FOUCAULT E DELEUZE: o que estamos fazendo de nós mesmos? Campinas, 22 a 24 de novembro de 2000. (mimeogr.)

ALMEIDA-FILHO, N.; COELHO, M.T. A. D.; PERES, M. F. T. O conceito de Saúde Mental. Rev. USP, v.43, p.100-25, 1999.

BIBEAU, G..; CORIN, E. Culturaliser l'épidémiologie psychiatrique. Les systèmes de signes, de sens et d'action en santé mentale. In: CHAREST, P.; TRUDEL, F.; BRETON, Y. (Dir). Marc-Adélard Tremblay ou la construction de l'anthropologie québécoise. Quebec: Presses de L'Université Laval, 1994. p.3-44.

BIBEAU, G. New and old trends in the interface between ethnography and psychiatry. In: NATIONAL MEETING ON MEDICALANTHROPOLOGY, 1., 1993. Salvador. November 3-6, 1993. (mimeogr.) 
PERES, M. F. T.; ALMEIDA-FILHO, N.

tiempo. In: CONGRESSO DE ANTROPOLOGIA EN COLOMBIA, 6., 1992. Sta. Fé de Bogota, Universidad de los Andes, julio 22-25, 1992. (mimeogr.)

BIBEAU, G. A step toward thick thinking: from webs of significance to connections across dimensions. Med. Anthropol Q., v. 2, p. 402-16, 1988.

BIRMAN, J. Entre cuidado e saber de si: sobre Foucault e a psicanálise. Rio de Janeiro: RelumeDumará, 2000.

CORIN, E. Les détours de la raison: repères sémiologiques pour une anthropologie de la folie. Anthropol. Soc., v. 17, n.1-2, p.5-20, 1993.

CORIN, E.; BIBEAU, G.; UCHÔA, E. Éléments d'une sémiologie anthropologique des troubles psychiques chez les Bambara, Soninké et Bwa du Mali. Anthropol. Soc., v. 17, n.1-2, p.125-56, 1993.

CORIN, E.; BIBEAU, G.; MARTIN, J. C.; LAPLANTE, R. Comprendre pour soinger autrement: repères pour régionaliser les services de santé mentale. Montréal: Presses de L'Université de Montréal, 1990.

CORIN, E. Vers une réouverture sémiotique et culturelle du diagnostic psychiatrique. In: BEUF, P. (Coord.) La santé mentale comme observable. Montréal: Ed. Colloque INSERM 192, 1989. p.45570.

FABREGA, H. Cultural relativism and psychiatric illness. Nervous Mental Dis., v.177, n.7, p.415- 25, 1989.

FOUCAULT, M. Em defesa da sociedade: curso no Collège de France (1975-1976). São Paulo: Martins Fontes, 1999.

FOUCAULT, M. A arqueologia do saber. Rio de Janeiro: Forense Universitária, 1995a.

FOUCAULT, M. História da loucura. São Paulo: Perspectiva, 1995b.

FOUCAULT, M. A governamentalidade. In: FOUCAULT, M. Microfísica do Poder. Rio de Janeiro: Graal, 1995c. p.277-93.

FOUCAULT, M. Le sujet et le pouvoir (1982) In: DEFERT, D.; EWALD, F. (Eds.) Michel Foucault, dits et écrits. Paris: Gallimard, 1994a. p.222-43.

FOUCAULT, M. Les techiniques de soi (1988) In: DEFERT, D.; EWALD, F. (Eds.) Michel Foucault, dits et écrits. Paris: Gallimard, 1994b. p.783-813.

FOUCAULT, M. História da sexualidade 2: o uso dos prazeres. Rio de Janeiro : Graal, 1994c.

FOUCAULT, M. As palavras e as coisas: uma arqueologia das ciências humanas. São Paulo: Martins Fontes, 1981.

FOUCAULT, M. L'ordre du discours. Paris: Gallimard, 1971.

FOUCAULT, M. Naissance de la clinique. Paris: PUF, 1963.

GOOD, B. J. Medicine, rationality and experience: an anthropological perspective. Cambridge: University Press, 1994.

GOOD, B.; GOOD, M. J. D. Toward a meaning-centered analysis of popular illness categories: 'fright illness' and 'heart distress' in Iran. In: MARSELLA, A. J.; WHITE, G.M. (Eds.) Cultural conceptions of mental health and therapy. London: Oxford University Press, 1982. p.141-66.

GOOD, B.; GOOD, M. J. D. The meaning of symptoms: a cultural hermeneutic model for clinical practice. In: EINSENBERG, L.; KLEINMAN, A. (Eds.) The relevance of social science for medicine. London: Oxford University Press, 1980. p.165-96.

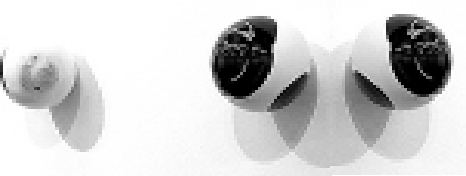


KLEINMAN, A. Depression, somatization and the 'new cross-cultural psychiatry. Soc. Sci. Med., v.11, p.3-10, 1977.

LITTLEWOOD, R. From category to context: a decade of the new cross-cultural psychiatry. Br. J.

Psychiatry, v.156, p.308-27, 1990.

RABINOW, P. Sujeito e governamentalidade: elementos do trabalho de Michel Foucault. In: RABINOW, P. Antropologia da razão. Rio de Janeiro: Relume-Dumará,1999. p.27-55.

YOUNG, A. The anthropologies of illness and sickness. Annu. Rev. Anthropol., v.11, p.257-85, 1982.
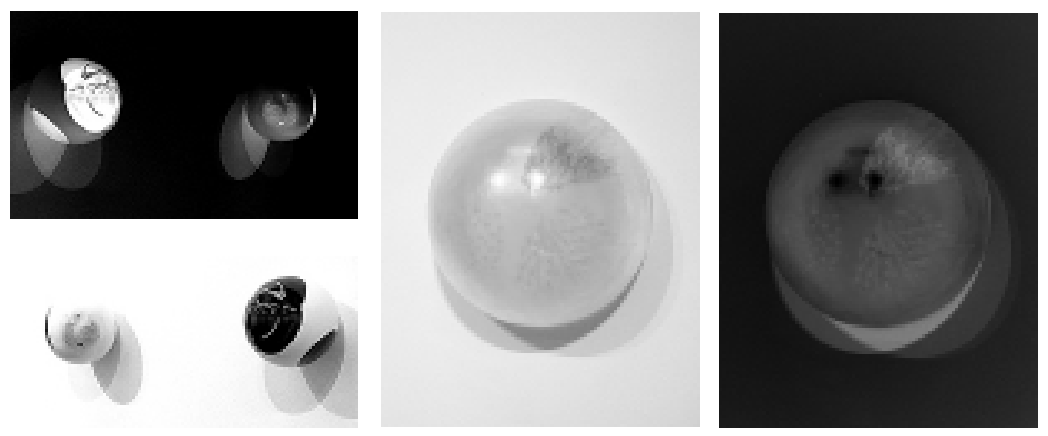

PERES, M. F. T.; ALMEIDA FILHO, N. La nueva psiquiatría transcultural y la reformulación en la relación entre las palabras y las cosas. Interface - Comunic., Saúde, Educ., v.9, n.17, p.275-85, mar/ago 2005.

La llamada "nueva psiquiatría transcultural" propone una reformulación en la relación entre las palabras y las cosas en el campo médico. Esta reformulación consiste en una lectura polisémica de la experiencia de enfermedad. En este artículo, nuestro objetivo es, a partir de una lectura foucaultiana, problematizar esta propuesta y apuntar sus limitaciones. Si se considera el enfoque que se da a la discursividad en el trabajo teórico de Foucault, es posible radicalizar la reformulación entre palabras y cosas; entre el discurso y el sentido; entre habla y sujeto hablante. A través de la noción de práctica discursiva el discurso adquiere materialidad y produce formas de subjetividad. Es en el orden discursivo que se instaura la experiencia de enfermedad y que se instituye el sujeto enfermo; que la enfermedad surge como un acontecimiento y se hace presente como "desgobierno".

PALABRAS CLAVE: nueva psiquiatría transcultural; experiencia de enfermedad; desgobierno; salud mental; antropología médica. 


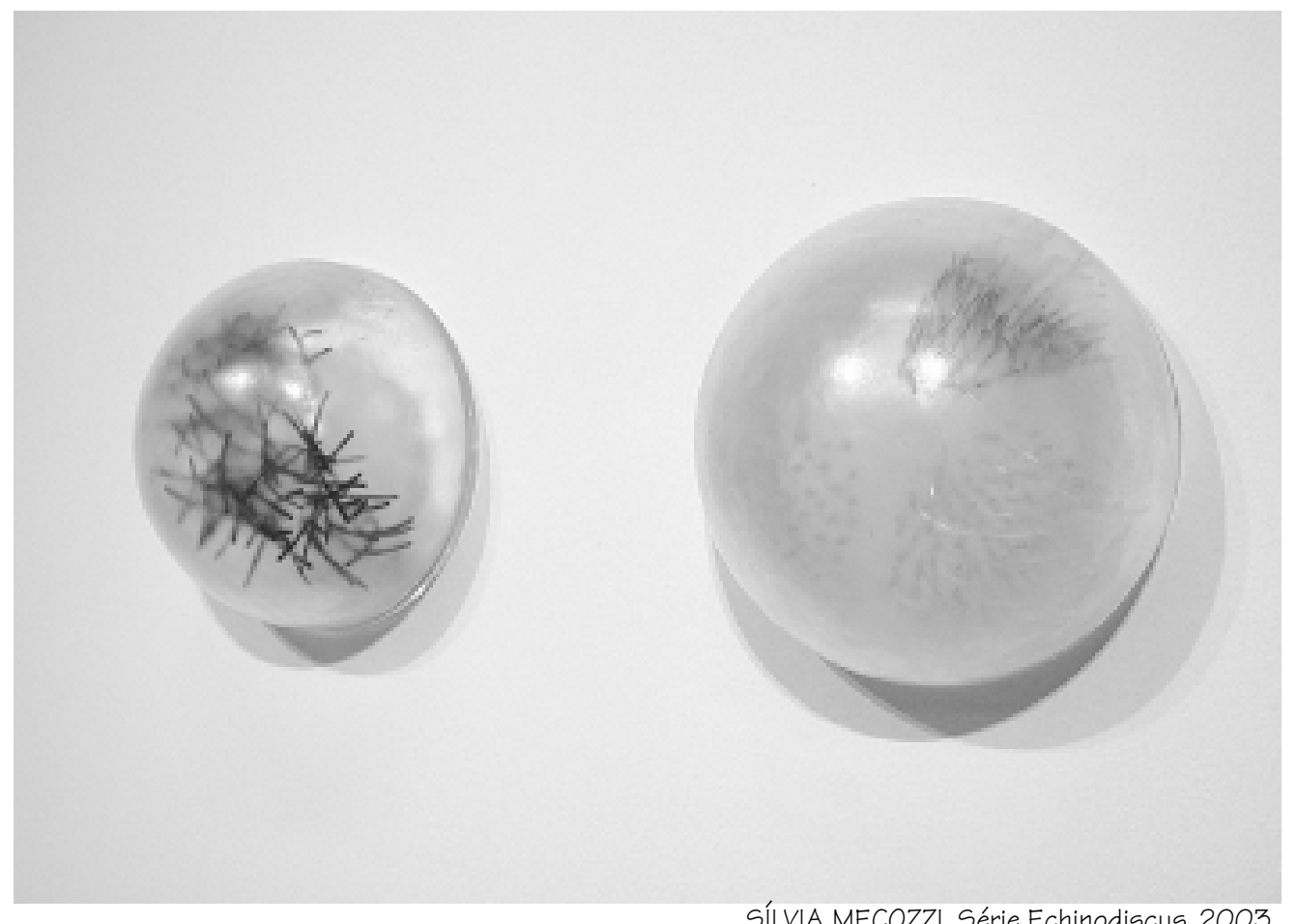

SÍLVIA MECOZZI, Série Echinodiscus, 2003 